\title{
Changing the ward culture in a clinic during the implementation of person-centred care
}

\author{
Axel Wolf*1,2, Kerstin Ulin ${ }^{1,2}$, Eric Carlström ${ }^{1,2}$ \\ ${ }^{1}$ Institute of Health and Care Sciences, Sahlgrenska Academy, University of Gothenburg, Gothenburg, Sweden \\ ${ }^{2}$ Gothenburg Centre for Person Centred Care (GPCC), University of Gothenburg, Gothenburg, Sweden
}

Received: July 13, 2017

DOI: $10.5430 /$ jha.v6n5p31
Accepted: September 10, $2017 \quad$ Online Published: October 10, 2017

URL: https://doi.org/10.5430/jha.v6n5p31

\begin{abstract}
Objective: The purpose of this study was to explore the impact of an intervention on the organizational culture in five hospital wards in Sweden. The organizational culture was measured at the start of the project and compared with data collected five years later. The intervention was aimed at changing activities towards a new evidenced-based care model called the Gothenburg Person-centred Care model (PCC).

Methods: In total, 230 registered nurses and assistant nurses participated in this cross-sectional health-care culture survey during 2009 and 2014. The Organizational Values Questionnaire was used.

Results: The results indicated cultural change in all five wards at the clinic. A dominating culture of flexibility decreased and a culture of routines and structure increased. The wards moved towards a higher degree of cultural uniformity. The combination of cultural dimensions also seems to have become more equal during the study period.

Conclusions: Few studies have focussed on the development of organizational culture in health-care contexts over time. The results suggest that the implementation of a new model of care has an impact on organizational culture. This implies that health-care managers should have confidence in the outcomes from change projects. It seems that systems of dual logic can develop over time to facilitate change and sustainability. However, if a new working model is to change the culture profoundly, it requires years of zealous implementation.
\end{abstract}

Key Words: Organizational culture, Cultural change, Change, Patient-centred care, Person-centred care, Implementation

\section{INTRODUCTION}

The implementation of new working models and new technology has often been hindered by conservative cultures and change-resisting behaviour. ${ }^{[1,2]}$ This has also proven to be the case in public health-care organizations. ${ }^{[3]}$ Professional territorialism and organizational inertia have been identified as reasons for slow routines and path dependency. ${ }^{[4,5]} \mathrm{Nev}-$ ertheless, changing existing practices is possible, although this requires a holistic approach targeting the specific context and groups, including key stakeholders such as health-care professionals, as well as line managers and top-level management. ${ }^{[1,6,7]}$

Sweden, where the data used in this study were collected, has old and comprehensive public health-care structures. Roots dating back to the $16^{\text {th }}$ century, ${ }^{[8]}$ deeply embedded traditions and conservatism are suggested reasons for slow, sequential work methods, even though Sweden has a technically modern, well-developed health-care system. ${ }^{[9,10]}$ While

\footnotetext{
*Correspondence: Axel Wolf; Email: axel.wolf@gu.se; Address: Institute of Health and Care Sciences, Sahlgrenska Academy; Gothenburg Centre for Person Centred Care (GPCC), University of Gothenburg, Gothenburg, Sweden.
} 
Sweden is ranked amongst the top countries in the Western world in terms of its health-care system, ${ }^{[11]}$ patients' perceptions in terms of participation and co-ordination have been broadly critical. ${ }^{[12,13]}$

Increasing queues for treatment, overcrowded emergency departments and slow patient turnover in hospital departments has raised awareness of the need to improve resource allocation, logistics and management techniques to better distribute resources. Therefore, it is important to find methods that meet the patients' needs and improve the efficiency of the health-care system, ${ }^{[14]}$ hence the introduction of personcentred care (PCC), an evidence-based approach that increases patient participation, which has been receiving attention around the world. However, as yet little is known about how to implement research findings in clinical practice. In this study, we investigate the long-term change in organizational culture in a hospital department following the implementation of the Gothenburg Person-Centred Care (gPCC) model in a university hospital.

\subsection{Background}

Organizational cultures in public organizations are suggested to be backward looking, inducing inertia and maintaining existing social structures. ${ }^{[15,16]}$ Discussions on the role of organizational culture in change processes and, conversely, the impact of change on organizational culture are seldom based on empirical findings. ${ }^{[17]}$ This area remains under-explored and in need of empirical investigation. ${ }^{[18]}$

The purpose of this study is to contribute to the discussion on how changeable organizational cultures are in response to the deliberate implementation of PCC. Earlier, we studied the co-variation between organizational culture and the employee's willingness to participate in change processes when implementing a new working model, i.e. the gPCC model. ${ }^{[19,20]}$ The idea was to estimate the possible impact of organizational culture on the implementation process in a hospital clinic. In this study, we returned to the department five years after the initial investigation, ${ }^{[21]}$ and once again measured the cultural characteristics to trace the effects of the model that had been implemented. The study is based on the presumption that change processes have a potential impact on organizational culture.

\subsection{The concept of stable cultures}

Culture is identified as an important change-resisting factor by virtue of its stability. ${ }^{[22]}$ Hospital wards have been shown to develop their own culture, and the cultures of various wards are mirrored in the overall hospital culture. ${ }^{[23]}$ Culture has been shown to have a substantial effect on an employee's performance, ${ }^{[23]}$ because change represents a situation of imbalance, and is considered a threat. ${ }^{[24,25]}$ This relationship is especially evident in public organizations, which are stable and rarely threatened by bankruptcy. In health care, even when it is a multi-professional environment, the predominating logic has proven to be biomedical, and hence skewed towards traditional power structures that favour the logic of medicine. ${ }^{[26]}$

\subsection{Changing cultures}

Implementation of change and improvement is not easily achieved in any organization, let alone a complex context such as a hospital. ${ }^{[27]}$ Culture, as defined by Kleinman, ${ }^{[28]}$ involves the interplay of structures such as protocols, routines and standards, as well as attitudes, beliefs and rituals. Organizational culture has been described as a collection of subcultures characterized by contradictions and ambiguity. ${ }^{[29]}$ The inner diversity of cultures is considered to contribute to conflicts that are important in the development of change processes. ${ }^{[30]}$ A diversity of organizational cultures has been identified in health-care settings and has been shown to improve communication, collaboration and co-ordination of activities. ${ }^{[31,32]}$ Xiao et al. ${ }^{[33,34]}$ described, for example, how integrative cultural components have supported rapid and dynamic collaboration in hospital teams.

However, attitudes, assumptions and values can differ between various management levels, and also between professional categories such as economists and physicians. It should not be taken for granted that people involved in a change process share the same goals or basic assumptions. Therefore, a shared cultural and structural understanding is an important aspect of a change management process.

Cultural variables have been shown to be of strategic importance during change processes. ${ }^{[34]}$ Thorne ${ }^{[35]}$ described physicians as cultural chameleons who have developed from medical representatives to hospital administrators through a cultural transition. Collectively, these physicians have undergone hybridization and embraced a new identity. ${ }^{[36]}$ It has been suggested that economists have influenced physicians to downplay the medical imperatives that previously characterized the profession. ${ }^{[37]}$ In addition, Rombach and Berglund ${ }^{[38]}$ argued that a culture influenced by economists has emerged in the health-care industry to replace a culture based on medical traditions.

Gauthereau $^{[39]}$ showed how cultures in hospital wards have moved towards a patient safety focus. He also describes emerging cultures of flexibility contributing to the caretaking processes. Moreover, Miller and Xiao ${ }^{[40]}$ suggested that cultures supporting workflow and decision-making processes have developed in hospital settings during the last two 
decades. As pointed out by Egel-Zanden and Rosen, ${ }^{[41]}$ implementation and innovation within complex environments should include both an element of clear intention from the management team (strategy-as-deliberate) and an element of freedom to operate and adapt (strategy-as-managed) for the people close to the day-to-day problems. Thus, it could be said that strategy-as-deliberate defines a top-down approach built on the notion of adherence, while strategy-as-managed defines the group's/organization's ability/need to define their own change and to adapt the change process towards their own beliefs and emergent ideas. ${ }^{[2]}$ Strategy-as-managed implies the accountability of individuals within the context to innovate and drive change towards a common goal. Therefore, top-down and bottom-up processes must interact and merge to achieve sustainable change.

\subsection{Theoretical framework}

Even though theories have been developed about organizational inertia in public health care, little is known about cultural change. ${ }^{[1]}$ One common model identifying culture in hospital settings is the competing values framework $(\mathrm{CVF}){ }^{[43,44]}$ This model arranges the principles of organizational effectiveness in four value dimensions. One of the value dimensions describes the organizational structure, from valuing flexibility at one end to valuing stability and control at the other end. Another value dimension deals with the organizational focus ranging from an external focus that places a higher value on the well-being and development of the organization itself to an internal focus, which places a higher value on the well-being and development of individuals within the organization. The model is based on the idea that organizational culture consists of a mix of opposing values. After reviewing 1,700 records to identify important quantitative measures of organizational culture in health care, Scott et al. ${ }^{[45]}$ suggested that the CVF was one of the two most influential instruments. The model has been shown to be based on relevant theories, i.e. a Jungian framework, in contrast to other instruments produced mainly on the basis of creativeness. Scott et al. ${ }^{[45]}$ emphasized that the CVF is especially appropriate when comparing the different cultures represented in health-care settings.

The framework includes four organizational characteristics that shape the culture; open systems (OS), human relations (HR), internal processes (IP) and rational goals (RG). OS is characterized by curiosity and willingness to try something new. An OS ward runs experiments and is occupied by benchmarking. An HR ward has a flat structure and is identified by its cohesion, trust, belongingness and flexibility. A hospital ward with a strong IP character seeks stability and continuity by sustaining routines, control, rules and hierarchies. An RG

Published by Sciedu Press culture is one in which goal-setting, competiveness, effectiveness and efficiency are preferred. ${ }^{[46]}$ The Organizational Values Questionnaire (OVQ) developed by Reino et al. ${ }^{[47]}$ used in this study is based on Cameron and Quinn's CVF (see Table 1).

Table 1. Cultural settings in a two-dimensional framework

\begin{tabular}{lll}
\hline & Control & Flexibility \\
\hline Internal & Internal Processes (IP) & Human Relations (HR) \\
External & Rational Goals (RG) & Open Systems (OS) \\
\hline
\end{tabular}

Several studies using the OVQ have identified Swedish hospital culture as being dominated by HR, i.e. flexibility, cohesion and trust. Such a culture has also been shown to correlate with change willingness. ${ }^{[21,48-50]}$ Furthermore, Carlström and Olsson ${ }^{[49]}$ found that RG and IP cultures, i.e. those that favour planning, routines and goal-setting, are positively correlated with increasingly change-resistant behaviour.

Quinn and Rohrbaugh ${ }^{[44]}$ found that effective organizations display contradictory cultures, i.e. flexibility (HR and OS) and stability (RG and IP), simultaneously. This is in accordance with the findings of Alharbi et al., ${ }^{[16,48]}$ who suggested that a flexible culture (HR) supports change, while a culture that values control, planning and goal-setting (IP and RG) may be able to sustain the desired outcomes resulting from the implementation of something new. Therefore, if an organization can balance these opposing cultural characteristics, it has a chance to successfully implement change and sustain the new models that are created (see Figure 1).

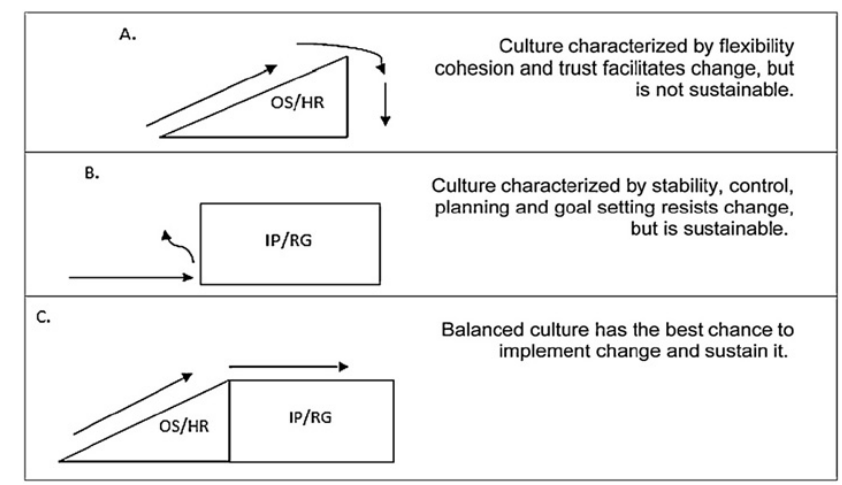

Figure 1. Optimal cultural balance to support and sustain change ${ }^{[48]}$

Several studies imply the importance of diversity. Complex, contradictory and sometimes paradoxical organizational cultures have proven to be more productive than cultures dominated by one of the extremes of either flexibility or stability. ${ }^{[50]}$ Brorström and Siverbo ${ }^{[10]}$ underscored the importance of being both stable and able to change at the same time, especially during health-care reforms. There is a simultaneous 
need to impede progress and maintain a certain degree of continuity and stability. ${ }^{[51]}$ This is in agreement with Glisson et al., ${ }^{[52]}$ who demonstrated that organizations with mixed cultural profiles sustain new treatment or service programmes more than twice as long as organizations with a narrow set of dominating cultures.

\section{MeTHODS}

\subsection{Research design}

The studied department consisted of five wards in a university hospital in western Sweden. The department experienced extensive change during the period 2009 to 2014. All five wards were participants in a research project that evaluated the effects of PCC. ${ }^{[53]}$ The model combines an ethical framework of acknowledging the patient as a capable and resourceful partner with expert knowledge about his/her everyday life, goals and motivation with a structured clinical pathway that is supported and developed by the health plan. Three routines operationalize this approach: (1) carefully structuring and listening to the patient's story to understand each person's condition and obstacles to achieving good health; (2) establishing a partnership of mutual respect between the patient as a capable person and the health-care professional; and (3) placing emphasis on a person being free, but interdependent rather than independent, when formulating a health plan. ${ }^{[19]}$

Following the conclusion of the research project, a change implementation process commenced in 2012 and continued until 2014. All five wards received a change management module that was influenced by Kotter's dual leadership system. ${ }^{[53]}$ Briefly, Kotter's concept built on the notion that strategy was both deliberate and emergent, and that a strategically selected group of participants representing different layers and roles in the organization (for example, a ward) should work autonomously to drive the change process. Each ward underwent a 10-week change management programme with the goal of implementing PCC. The 10-week programme consisted of five workshops that included lectures about the gPCC model, the philosophy of the person, methods for change management, appreciative inquiry technique and presentation of tools and protocols (e.g. health-care plans and rating scales) used in the research study that preceded the implementation process. An important aspect of the change process was that the gPCC model was an ethical working tool, but wasn't necessarily seen as a blueprint to which the various wards needed to adapt. Each ward had the opportunity to develop PCC in their own way through an emergent process.

Each ward management team selected a specific mix of change agents consisting of physicians, registered nurses (RNs) and assistant nurses (ANs). The project embraced far-reaching changes to work routines and influenced all the health-care professionals in the wards. The ultimate objective was to reinforce the central role of the patient in the clinical encounter and to make the patient's view the point of departure in care planning. Each patient's healthplan recognized the interaction of biological, psychological and socio-cultural factors to create a predictive development from admission to discharge and onwards. It was developed in response to criticism of the existing biomedical model, which was seen as a cause of prolonged hospital stays and unscheduled return visits.

The pilot project started in spring of 2012 and covered three wards including a total of 23 health-care professionals, including the management team. The second change management programme started in autumn of 2012 on the fourth ward (which included 12 clinicians and managers). The change management programme commenced on the fifth ward (which included 23 health-care professionals and managers) in autumn of 2013. All change management programs followed the same 10-week structure regarding workshops, steering group meetings and assignments such as patient interviews, health-care-plan workshops, training in ethics and the philosophy of the person. The main aim of the change management programme was to design and test aspects of PCC that the ward found interesting and could make their own. All wards had the opportunity to share their ideas and borrow from each other.

\section{Measures}

The survey was conducted using the OVQ developed by Reino. ${ }^{[47]}$ The OVQ is based on the CVF measuring the four dimensions OS, HR, IP and RG. It contains 52 items measured on a 10-point Likert-type scale ranging from "strongly disagree" (1) to "strongly agree" (10).

\subsection{Procedure}

The first-line nurse managers of the clinical wards were informed about the study. Letters explaining the aim of the study together with a self-reported questionnaire collecting descriptive data were sent out by email using the employees' work email address. The first email reminder was sent three weeks later. If no response had been received after four weeks, a final reminder in the form of a paper survey and a pre-labelled envelope was placed in the employee's mailbox. The completed questionnaires were returned to the authors, and the respondents' anonymity was maintained.

The survey included RNs and ANs, as well as physicians. To enable a comparison with the study conducted in 2009, we excluded the physicians from the second analysis. The response rate was 69\% in 2009 and $40 \%$ in 2014. Informed 
consent was obtained from the manager of the department before the study commenced and each respondent received written information explaining the purpose of the survey and was able to choose whether to participate.

The homogeneity of the items in the sub-scales was analysed using Cronbach's alpha. The results varied between 0.66 and 0.88 , which is considered to be satisfactory. The surveys were numbered and variables were defined using Statistical Package for the Social Sciences (SPSS) version 17.0 and IBM SPSS Statistics version 22.0. Statistical significance was established at $p<.05$. The analysis was based primarily on descriptive data. Means and standard deviations were used for descriptive purposes.

\subsection{Participants}

In 2009, a total of 117 nurses participated in the study. Of those, $105(89 \%)$ were female and $12(11 \%)$ were male. Their ages ranged from 23 to 63 years (mean $[\mathrm{M}]=38.9$, standard deviation $[S D]=9.9)$. Seventy-two $(62 \%)$ were RNs and 45 (38\%) were ANs. Their professional experience ranged from 0.5 years to 38 years $(M=11.5, S D=10.2)$. The total number of respondents in 2014 was 113, of which $101(89 \%)$ were female and eight $(7 \%)$ were male, while four respondents did not answer the gender question. Their ages ranged from 20 to 63 years $(M=40.4, S D=12.2)$. Seventy (62\%) were RNs and 43 (38\%) were ANs. Their professional experience ranged from 0.5 to 41 years $(\mathrm{M}=13.2$, $S D=11.6)$.

\subsection{Ethical considerations}

The ethical code of conduct followed and conformed to the ethical guidelines adopted by the Swedish Research Council and conforms to the principles outlined in the Declaration of Helsinki. In accordance with Swedish ethical require- ments, no ethical approval by a regional ethical review board was required for this kind of investigation. All respondents received written information about the study together with the survey, including information about confidentiality and voluntariness of study participation.

\section{RESULTS}

HR was the most prominent dimension in the study conducted in 2009 ( $\mathrm{M}=7.1, S D=1.1)$, closely followed by RG $(\mathrm{M}=6.4, S D=1.0)$, OS $(\mathrm{M}=6.3, S D=1.2)$ and IP $(\mathrm{M}=5.9, S D=0.8)$. In 2014, even though it had decreased, HR was still the most prominent dimension $(M=6.8$, $S D=1.4)$, while the others had all increased (RG: $\mathrm{M}=6.5$, $S D=1.4$, OS: $\mathrm{M}=6.4, S D=1.5$ and IP: $\mathrm{M}=6.2, S D=1.0$ ) (see Table 2).

This shows that even though a culture of flexibility, cohesion, trust and belongingness (HR) was still dominant among the health-care workers, HR showed an overall decrease in 2014 compared with 2009. Conversely, IP, i.e. a culture of stability, control and routines, had increased, contributing to a decreased cultural range, i.e. a more coherent cultural distribution in 2014 than in 2009 (see Table 3).

The results show that the cultural characteristics were more equal in 2014 than in 2009, i.e. the culture had achieved a higher degree of coherence between the four competing values, OS, HR, IP and RG. HR decreased over the fiveyear period, while IP increased. The greater the diffusion of characteristics in the wards, the greater the change towards a higher degree of coherence in cultural diversity (wards two and three). Wards one and five showed the least change among the five wards, while the range increased in ward three. Overall, the cultural range in the clinic decreased from 1.2 to 0.6 during the five-year survey period (see Figures 2 and 3$)$.

Table 2. Mean values for responses to the OVQ, divided into sub-scales and hospital wards, in $2009(\mathrm{n}=117)$ and $2014(\mathrm{n}$ $=113)$

\begin{tabular}{lllllll}
\hline OVQ sub-scale 2009 (2014) & Ward 1 & Ward 2 & Ward 3 & Ward 4 & Ward 5 & All \\
\hline Open Systems (OS) & $6.5(7.0)$ & $5.4(5.8)$ & $6.2(5.8)$ & $7.2(6.7)$ & $6.1(6.7)$ & $6.3(6.4)$ \\
Human Relations (HR) & $6.85(6.9)$ & $6.45(6.0)$ & $6.75(6.9)$ & $8.1(7.3)$ & $7.4(7.1)$ & $7.1(6.8)$ \\
Internal Processes (IP) & $6.5(6.5)$ & $5.6(6.15)$ & $6.1(6.1)$ & $5.9(5.8)$ & $5.65(6.3)$ & $5.9(6.2)$ \\
Rational Goals (RG) & $7.0(7.2)$ & $6.1(6.3)$ & $6.2(6.1)$ & $6.6(6.4)$ & $6.1(6.3)$ & $6.4(6.5)$ \\
All & $6.7(6.9)$ & $5.9(6.1)$ & $6.3(6.2)$ & $6.9(6.6)$ & $6.3(6.6)$ & \\
\hline
\end{tabular}

Table 3. Cultural range in $2009(\mathrm{n}=117)$ and $2014(\mathrm{n}=113)$

\begin{tabular}{lllllll}
\hline & Ward 1 & Ward 2 & Ward 3 & Ward 4 & Ward 5 & All \\
\hline 2009 & 0.45 & 1.09 & 0.67 & 2.23 & 1.77 & 1.2 \\
2014 & 0.72 & 0.36 & 1.04 & 1.45 & 1.77 & 0.6 \\
\hline
\end{tabular}




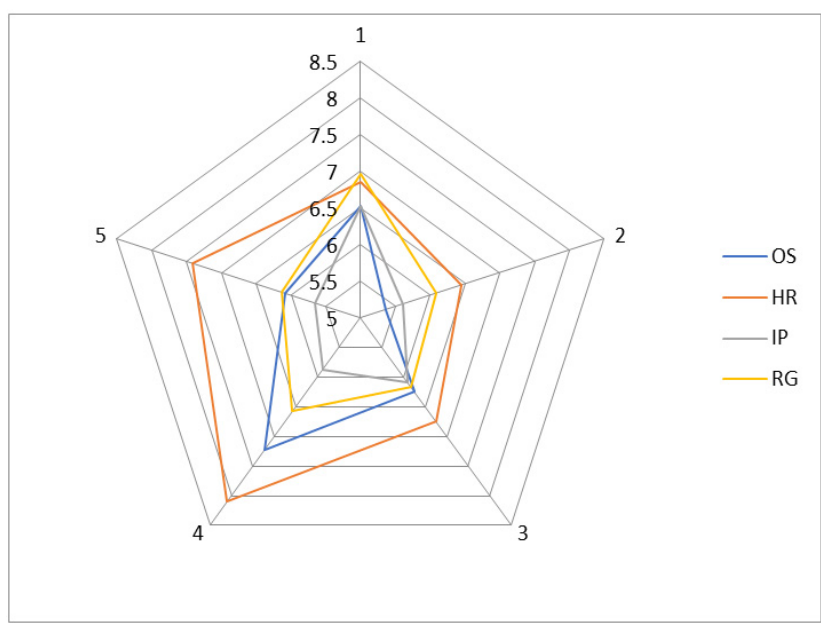

Figure 2. OVQ sub-scale distribution over the five wards in 2009

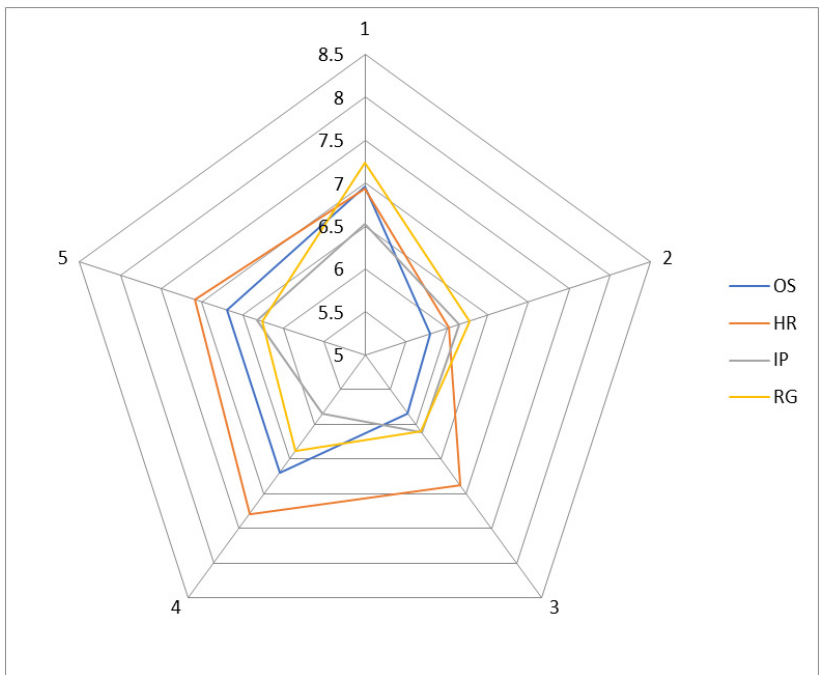

Figure 3. OVQ sub-scale distribution over the five wards in 2014

\section{Discussion}

The results showed that HR, i.e. a culture of flexibility and trust, dominated the hospital ward culture, and yet it is evident that the clinic underwent a cultural change towards decreased diversity between the wards, with more stability and cultural balance. The dominating culture of flexibility, cohesion and trust decreased, leaving space for an increase in routines and structure. The cultural dimensions became more equal during the study, implying a lower degree of cultural diversity than had existed five years earlier. Based on Johansson et al., ${ }^{[49]}$ who noted that contradictory organizational cultures have proven to be productive during change processes, the results suggest that a change process can impact the organizational culture. In accordance with Broström and Siverbo, ${ }^{[10]}$ who emphasized the importance of being both stable and able to change at the same time during health-care reforms, the culture in the wards changed to a more recipient and sustaining mood than existed at the beginning of the change project. Even though the wards had an opportunity to adopt their own approach to the gPCC model, structures and routines seemed to increase during the project. A plausible interpretation of these results is that organizations can improve the mix of cultures to implement and sustain a new working model. Glisson et al. ${ }^{[51]}$ have shown that organizations with mixed cultural profiles sustain new treatment or service programmes twice as long as organizations with unfavourable cultures, and Quinn and Rohrbaugh ${ }^{[42,43]}$ suggested that effective organizations are able to accommodate contradictory cultures.

Alharbi et al. ${ }^{[16,47]}$ showed that although it was easier to introduce changes in a flexible environment, there was no guarantee that the changes could be sustained. A flexible environment was indeed conducive to the introduction of the gPCC model, but there were trends suggesting that the organization returned to old and well-established processes some time later. Thus, there was a lack of stamina for change. Conversely, a mechanistic environment, i.e. stability, control and routines, showed resistance to innovation. However, the mechanistic environment had the ability to maintain routines and stable characteristics over the long term. Based on these results, Alharbi et al. concluded that a combination of both flexible and mechanistic logic is optimal, i.e. the ability to introduce change along with the ability to maintain innovation over time through standardization and protocols. In the present study, it seems as though the implementation over the long run nourished a more routine-based approach without losing the relational and open-system approach. While this might seem counterintuitive, it could also show that systems of dual logic (structured vs. ad hoc) can work side by side.

Koren ${ }^{[54]}$ suggested that cultural change in health care is a long and slow process. She describes the development of a close patient-health-care professional relationship, staff empowerment and collaborative decision-making as a 25 year journey before results can be measured. Kline ${ }^{[55]}$ was even more pessimistic, arguing that health-care staff cannot change a conservative culture of poor patient care, but need to be more outspoken if they are to induce changes. However, very little is known about the development of cultures during changes in hospital settings. ${ }^{[13]}$

We suggest that the implementation of PCC is the main reason for the cultural change we identified in this study. However, there are several other possible reasons. Carlström and Olsson ${ }^{[48]}$ suggested that certain management conditions are required before cultural change can be contemplated. 
They recommend a system of so-called good people management to achieve high performance in hospital settings. Team training has been identified as one of the most important requirements for cultural change. Team training is an important part of the gPCC model, and was undertaken intensively in the hospital wards during the study period. Even though it is still only a hypothesis that the cultural change we identified is an effect of the implementation of PCC, the study shows that even though the public health-care system in Sweden is regarded as highly conservative and characterized by organizational inertia, ${ }^{[8,9]}$ it seems to be capable of change. The results of this study indicate that a receptive hospital culture during the implementation of a new working model can develop an ability to sustain the implemented model. This five-year retrospective study showed a cultural change during an implementation process in five hospital wards. However, more long-term research in other hospital clinics is needed to verify the results obtained in this study.

\subsection{Limitations}

No professional category other than RNs and ANs participated in the study. This was a result of the design of the original study in 2009. This, of course, excluded key stakeholders such as physicians and physiotherapists, although one could argue that the RN's position is that of "the spider in the web" in a hospital ward because the RN is included in almost every aspect of patient care, and ANs are often regarded as the professional group closest to the patient, performing basic nursing care. The RNs act as a bridge between the ANs and physicians and other applied health-care professionals. However, the inclusion of physicians could produce different results when measuring the organizational culture. Another limitation is the low response rate (40\%) for the follow-up study in 2014. This is an important limitation, although because the study was a follow-up study, the lower response rate is still feasible in terms of comparing the results obtained with those from 2009.

\subsection{Implications}

The results suggest that the implementation of new models has an impact on organizational culture, and imply that managers should have confidence regarding the outcome of change projects. It seems that a system of dual logic can develop over time to facilitate change and sustainability. However, if a new working model is to change the culture profoundly, it requires years of zealous implementation.

\section{Conclunions}

Even though the public health-care system in Sweden is regarded as highly conservative and characterized by organizational inertia, it is capable of change. In this study, we showed how five hospital wards displayed a receptive culture during the implementation of a new working model and developed an improved ability to sustain the new model over a five-year period.

\section{ACKNOWLEDGEMENTS}

We thank Geoff Whyte, MBA, from Edanz Group for editing a draft of this manuscript.

\section{FUNDING}

The study was funded by the Centre for Person-Centred Care (GPCC) at the University of Gothenburg, Sweden. The GPCC is funded by the Swedish Government's grant for Strategic Research Areas, Care Sciences (Application to Swedish Research Council NO. 2009-1088) and co-funded by the University of Gothenburg, Sweden.

\section{Conflicts of InTEREST Disclosure}

The authors declare they have no conflicts of interest.

\section{REFERENCES}

[1] Carlström E. Strategies for Change - Adaption to new accounting conditions. Journal of Accounting \& Organizational Change. 2012; 8(1): 41-61. https://doi.org/10.1108/18325911211205739

[2] Brady D, Marquardt S, Gauchat G, et al. Path Dependency and the Politics of Socialized Health Care. J Health Polit Policy Law. 2016; 41(3). PMid: 26921380. https : //doi.org/10.1215/03616878 $-3523946$

[3] Arrow KJ. Uncertainty and the welfare economics of medical care. The American Economic Review. 1963; 53(5): 941-973.

[4] Wang V, Lee SYD, Maciejewski ML. Inertia in health care organizations: A case study of peritoneal dialysis services. Health Care Management Review. 2015; 40(3): 203-213. PMid: 24763206. https ://doi.org/10.1097/HMR.0000000000000024
[5] Powell M. Reforming a Health Care System in a Big Way? The Case of Change in the British NHS. Social Policy \& Administration. 2016; 50(2): 183-200. https ://doi.org/10.1111/spol.12210

[6] Berlin J, Carlström E. Traditions challenged by trends. A health care in metamorphosis. Scandinavian Journal of Public Administration. 2012; 16(2): 7-18.

[7] Grol R, Grimshaw J. From best evidence to best practice: effective implementation of change in patients' care. Lancet. 2003; 362(9391): 1225-30. https://doi.org/10.1016/S0140-673 6 (03) 14546-1

[8] Gustafsson RA. Origins of authority: the organization of medical care in Sweden. International Journal of Health Services. 1989; 19(1): 121-133. PMid: 2647647. https://doi.org/10.2190/K1RD-D O3B-ONHH-HOWY 
[9] Axelsson R. The organizational pendulum-healthcare management in Sweden 1865-1998. Scand J Public Health. 2000; 28(1): 47-53. PMid: 10817314. https://doi.org/10.1080/713797378

[10] Broström B, Siverbo S. Deeply rooted traditions and the will to change-problematic conflicts in three Swedish health care organizations. Journal of Economic Issues. 2004; 38(4): 939-952. https://doi.org/10.1080/00213624.2004.11506750

[11] Davis K, Schoen C, Schoenbaum SC, et al. Mirror, mirror on the wall. How the performance of the US Health care system compares internationally. New York: CommonWealth Fund, 2014.

[12] Berggren I, Carlström E. Decision making within a community provider organization. British Journal of Community Nursing. 2010; 15(12): 611. PMid: 21240088. https://doi.org/10.12968/bjc n. 2010.15.12.611

[13] Carlström E. Förändringsarbete i hälso-och sjukvård (Change management in health care organizations). Studentlitteratur. 2013.

[14] Olofsson P, Gellerstedt M, Carlström ED. Manchester triage in Sweden-interrater reliability and accuracy. International Emergency Nursing. 2009; 17(3): 143-148. PMid: 19577200. https://doi.org/ $10.1016 / j$.ienj . 2008.11.008

[15] Vygotsky LS. Mind in society: The development of higher psychological processes. Harvard University Press; 1980.

[16] Ts JA, Olsson LE, Ekman I, et al. The impact of organizational culture on the outcome of hospital care: after the implementation of person-centred care. Scandinavian Journal of Public Health. 2014; 42(1): 104-10.

[17] Scott-Findlay S, Estabrooks CA. Mapping the organizational culture research in nursing: a literature review. Journal of Advanced Nursing 2006; 56(5): 498-513. PMid: 17078826. https ://doi.org/10.1 $111 / j .1365-2648.2006 .04044 . x$

[18] Jacobs R, Mannion R, Davies HT, et al. The relationship between organizational culture and performance in acute hospitals. Social Science \& Medicine. 2013; 76(1): 115. PMid: 23159305. https: //doi.org/10.1016/j.socscimed.2012.10.014

[19] Britten N, Moore L, Lydahl D, et al. Elaboration of the Gothenburg model of person-centred care. Health Expectations. 2016; 20(3): 407418. PMid: 27193725 . https://doi.org/10.1111/hex.12468

[20] Naldemirci Ö, Wolf A, Elam M, et al. Deliberate and emergent strategies for implementing person-centred care: a qualitative interview study with researchers, professionals and patients. BMC Health Serv Res. 2017; 17(1): 527. PMid: 28778167. https: //doi.org/10.1186/s12913-017-2470-2

[21] Carlström E, Ekman I. Organisational Culture and Change - Implementing person-centered care. Journal of Health Organization and Management. 2012; 26(2): 175-191. PMid: 22856175. https : //doi.org/10.1108/14777261211230763

[22] Schein EH. On dialogue, culture, and organizational learning. Organizational Dynamics. 1993; 22(2): 40-51. https ://doi . org/10.1 016/0090-2616 (93) 90052-3

[23] Berlin J, Carlström E. From artefact to effect: the organising effects of artefacts on teams. J Health Organ Manag. 2010; 24(4): 41227. PMid: 21033637 . https://doi .org/10.1108/1477726101 1065011

[24] Appelbaum SH, Wohl L. Transformation or change: some prescriptions for health care organizations. Managing Service Quality: An International Journal. 2000; 10(5): 279-298. https ://doi .org/10 $.1108 / 09604520010345768$

[25] Rozakis M. The cultural context of emergencies: Seeking for a(n) holistic approach on disaster management. Disaster Prevention and Management: An International Journal. 2007; 16(2): 201-209. https://doi.org/10.1108/09653560710739522
[26] Wolf A, Carlström E. Person-Centered Care: Prerequisites for change: Management, employeeship and organization, in Person-centredness in health care. I. Ekman, Editor. Liber: Stockholm; 2014. 113-129 p.

[27] Grol R, Wensing M, Eccles M, et al. Improving patient care: the implementation of change in health care. John Wiley \& Sons; 2013. https://doi.org/10.1002/9781118525975

[28] Kleinman A. The cultural meanings and social uses of illness: A role for medical anthropology and clinically oriented social science in the development of primary care theory and research. The Journal of Family Practice. 1983. PMid: 6827232.

[29] Martin J, Siehl C. Organizational culture and counterculture: An uneasy symbiosis. Organizational Dynamics. 1983; 12(2): 52-64. https ://doi .org/10.1016/0090-2616(83) 90033-5

[30] Truong M, Paradies Y, Priest N. Interventions to improve cultural competency in healthcare: a systematic review of reviews. BMC Health Services Research. 2014; 14(1): 99. PMid: 24589335. https://doi.org/10.1186/1472-6963-14-99

[31] Berlin J, Carlström E. The 90 second collaboration: A critical study of collaboration exercises at extensive accident sites. Journal of Contingencies and Crisis Management. 2008; 16(4): 173-181. https://doi.org/10.1111/j.1468-5973.2008.00548.x

[32] Berlin J, Carlström E. The 20-minute team-a critical case study from the emergency room. J Eval Clin Pract. 2008; 14(4): 56976. PMid: 18462281 . https://doi.org/10.1111/j.1365-275 3.2007.00919. $\mathrm{x}$

[33] Xiao Y, Lasome C, Moss J, et al. Cognitive properties of a whiteboard: A case study in a trauma centre. DBLP. 2001; 259-278. PMid: 11174315.

[34] Xiao Y, Plasters C, Seagull FJ, et al. Cultural and institutional conditions for high reliability teams. IEEE. 2004; 3: 2580-2585.

[35] Thorne ML. Cultural chameleons. British Journal of Management. 2000; 11(4): 325-39. https://doi.org/10.1111/1467-8551. 00176

[36] Kurunmäki L. A hybrid profession-the acquisition of management accounting expertise by medical professionals. Accounting, Organizations and Society. 2004; 29(3): 327-347. https://doi .org/10 .1016/S0361-3682(02) 00069-7

[37] Kurunmäki L, Miller p. Modernising government: the calculating self, hybridisation and performance measurement. Financial Accountability \& Management. 2006; 22(1): 87-106. https ://doi.org/ $10.1111 / j .0267-4424.2006 .00394 . x$

[38] Gauthereau V. Emergent structures in drug dispensing to inpatients: implications for patient safety. Cognition, Technology \& Work. 2004; 6(4): 223-238. https://doi.org/10.1007/s10111-004-015 $2-4$

[39] Miller A, Xiao Y. Multi-level strategies to achieve resilience for an organisation operating at capacity: a case study at a trauma centre. Cognition, Technology \& Work. 2007; 9(2): 51-66. https: //doi.org/10.1007/s10111-006-0041-0

[40] Egels-Zandén N, Rosén M. Sustainable strategy formation at a Swedish industrial company: bridging the strategy-as-practice and sustainability gap. Journal of Cleaner Production. 2015; 96: 139-147. https://doi.org/10.1016/j.jclepro.2014.01.072

[41] Mintzberg H, Waters JA. Of strategies, deliberate and emergent. Strategic Management Journal. 1985; 6(3): 257-272. https ://doi. org/10.1002/smj . 4250060306

[42] Quinn R, Rohrbaugh J. Competing Values Approach to Organisational Effectiveness. Public Productivity Review. 1981; 5: 122-140. https://doi.org/10.2307/3380029

[43] Quinn R, Rohrbaugh J. A spatial model of effectiveness criteria: Towards a competing values approach to organizational analysis. 
Management Science. 1983; 29(3): 363-377. https ://doi.org/ $10.1287 / \mathrm{mnsc} .29 .3 .363$

[44] Scott T, Mannion R, Davies H, et al. The quantitative measurement of organizational culture in health care: a review of the available instruments. Health Services Research. 2003; 38(3): 923-945. PMid: 12822919. https://doi .org/10.1111/1475-6773.00154

[45] Cameron KS, Quinn RE. Diagnosing and changing organizational culture: Based on the competing values framework. John Wiley \& Sons; 2005.

[46] Reino A, Kask T, Vadi M. Organizational culture and environment: Dynamics in dynamics. Case of Ordi. Trames. 2007; 11(2): 124-138.

[47] Alharbi TS, Ekman I, Olsson LE, et al. Organizational culture and the implementation of person centered care: results from a change process in Swedish hospital care. Health Policy. 2012; 108(2-3): 294-301. PMid: 23069131. https://doi.org/10.1016/j.heal thpol.2012.09.003

[48] Carlström E, Olsson LE. The association between subcultures and resistance to change-in a Swedish hospital clinic. Journal of Health Organization and Management. 2014; 28(4): 458-476. PMid: 25241594. https://doi.org/10.1108/JHOM-09-2012-0184

[49] Johansson C, Åström S, Kauffeldt A, et al. Culture as a predictor of resistance to change: a study of competing values in a psychiatric nurs- ing context. Health Policy. 2014; 114(2): 156-162. PMid: 23932351. https://doi.org/10.1016/j.healthpol.2013.07.014

[50] Berwick DM. Disseminating innovations in health care. JAMA. 2003; 289(15): 1969-1975. PMid: 12697800. https://doi.org/10.1 001/jama.289.15.1969

[51] Glisson C. Assessing and changing organizational culture and climate for effective services. Research on Social Work Practice. 2007; 17(6): 736-747. https://doi.org/10.1177/1049731507301659

[52] Ekman I, Wolf A, Olsson LE, et al. Effects of person-centred care in patients with chronic heart failure: the PCC-HF study. Eur Heart J. 2012; 33(9): 1112-9. PMid: 21926072. https://doi.org/10.1 093/eurheartj/ehr306

[53] Kotter JP. Accelerate! Harv Bus Rev. 2012. 90(11): 44-52, 54-8, 149. PMid: 23155997.

[54] Koren MJ. Person-Centered Care For Nursing Home Residents: The Culture-Change Movement. Health Affairs. 2010. PMid: 20056692. https://doi.org/10.1377/hlthaff .2009.0966

[55] Kline R. Stand up and be an agent for change. Nursing Standard. 2013; 27(24): 16-17. PMid: 23505891. https://doi.org/10.7 $748 / \mathrm{ns} 2013.02 \cdot 27.24 .16 . \mathrm{s} 6$ 